This is the peer reviewed version of the following article: Puzey, J. and Vallejo-Marín, M. (2014), Genomics of invasion: diversity and selection in introduced populations of monkeyflowers (Mimulus guttatus). Molecular Ecology, 23: 4472-4485. doi: 10.1111/mec.12875, which has been published in final form at http://onlinelibrary.wiley.com/doi/10.1111/mec.12875/abstract. This article may be used for non-commercial purposes in accordance With Wiley Terms and Conditions for selfarchiving. 


\section{Genomics of invasion: Diversity and selection in introduced populations}

2 of monkeyflowers (Mimulus guttatus)

3

4

5 Joshua Puzey ${ }^{1,2}$

6 Mario Vallejo-Marín ${ }^{3}$

7

$8{ }^{1}$ Department of Biology, Duke University, Durham, North Carolina, United States of America.

927705.

$10{ }^{2}$ Department of Biology, College of William and Mary, Williamsburg, Virginia, United States of

11 America. 23185.

$12{ }^{3}$ Biological and Environmental Sciences, University of Stirling. Stirling, Scotland, United

13 Kingdom. FK9 4LA. Email: mario.vallejo@stir.ac.uk

16 Keywords: anthropogenic dispersal; genome scan; introduced species; long-distance

17 colonisation; next generation sequencing; selective sweeps.

18 Running title: Genomic analysis of introduced monkeyflowers 


\section{ABSTRACT}

21 Global trade and travel is irreversibly changing the distribution of species around the world.

22 Because introduced species experience drastic demographic events during colonisation, and

23 often face novel environmental challenges from their native range, introduced populations may

24 undergo rapid evolutionary change. Genomic studies provide the opportunity to investigate the

25 extent to which demographic, historical, and selective processes shape the genomic structure of

26 introduced populations by analysing the signature that these processes leave on genomic

27 variation. Here we use next-generation sequencing to compare genome-wide relationships and

28 patterns of diversity in native and introduced populations of the yellow monkeyflower (Mimulus

29 guttatus). Genome resequencing data from ten introduced populations from the United

30 Kingdom (UK) and 12 native M. guttatus populations in North America (NA), demonstrated

31 reduced neutral genetic diversity in the introduced range, and showed that UK populations are

32 derived from a geographic region around the North Pacific. A selective-sweep analysis revealed

33 site frequency changes consistent with selection on 5 of 14 chromosomes, with genes in these

34 regions showing reduced silent site diversity. While the target of selection is unknown, genes

35 associated with flowering time and biotic and abiotic stresses were identified within the swept

36 regions. The future identification of the specific source of origin of introduced UK populations

37 will help determining if the observed selective sweeps can be traced to un-sampled native

38 populations or occurred since dispersal across the Atlantic. Our study demonstrates the general

39 potential of genome-wide analyses to uncover a range of evolutionary processes affecting

40 invasive populations. 


\section{INTRODUCTION}

42 The introduction of species beyond their native ranges can affect ecological and evolutionary

43 interactions in the new habitat (Cox 2004; Phillips \& Shine 2006; Liu \& Pemberton 2009;

44 Ricciardi et al. 2013), and can negatively impact levels of local biodiversity, and result in high

45 economic costs (Pimentel 2002; Williams et al. 2010; Vila et al. 2011). Introduced populations

46 are often used models to investigate rapid genetic changes and adaptation to novel

47 environments, thus providing valuable insights into basic biological processes including local

48 adaptation (Sax et al. 2007; Prentis et al. 2008). In particular, genetic analyses continue to play a

49 central role in studies of the origin and establishment of introduced populations, as well as of

50 the mechanisms that permit the colonisation and drive the spread of populations beyond their

51 native range (Baker \& Stebbins 1965; Lee 2002).

52 The genomic structure of non-native populations is influenced by a variety of processes

53 including population bottlenecks, multiple introductions, population expansion, gene flow

54 between populations, and selection, among others (Lee 2002). For instance, in populations

55 established after limited long distance dispersal events, the level of genetic diversity can be

56 significantly lower than in the native range, reflecting population bottlenecks (Lachmuth et al.

57 2010; Ness et al. 2012). However, introduction of multiple individuals from the same

58 population, or multiple introductions from genetically diverse source populations, can

59 counteract the loss of diversity or even result in higher levels of genetic variation within

60 introduced populations compared to native ones (Dlugosch \& Parker 2008). The level of

61 standing variation in introduced populations is relevant to the colonisation process, as severe 
62 bottlenecks and reduced diversity could indicate potential limitations for the rapid evolution of

63 adaptive traits in novel environments (Barrett \& Schluter 2008; Lachmuth et al. 2010; Siol et al.

64 2010; Messer \& Petrov 2013). Severe bottlenecks resulting in globally reduced diversity may

65 indicate that natural selection is mutation limited. However, genetic variation resulting from

66 introduction of multiple individuals can provide ample standing variation for natural selection.

67 Genome wide studies have been employed to investigate genetic patterns in natural

68 populations, including the relationship between native and introduced populations as well as

69 invasion pathways of exotic plants and animals (Jahodová et al. 2007; Dlugosch et al. 2013;

70 Tarnowska et al. 2013). Genome scans allow detecting selection acting on specific locations in

71 the genome (Nielsen et al. 2005), and by comparing the sites under selection in the genomes of

72 different populations, it is possible to identify candidates for genetic regions associated with

73 local adaptation (Savolainen et al. 2013). A prerequisite to any genome wide study is identifying

74 a large numbers of genetic markers, such as restriction site polymorphisms (e.g., AFLPs, Vos et

75 al. 1995), or single nucleotide polymorphisms (SNPs). The growing access to high-throughput

76 sequencing technologies at low costs opens the opportunity to conduct genome wide studies at

77 an unprecedented depth, even in non-model organisms (Prentis et al. 2010; Twyford \& Ennos

78 2012; Ellegren 2014).

79 The generation of genome wide markers by high throughput sequencing can employ

80 methods for genome complexity reduction such as transcriptome sequencing (Dlugosch et al.

81 2013) or RAD sequencing (Davey et al. 2011; Roda et al. 2013). However, for the increasing

82 number of species in which a reference genome is available, whole genome re-sequencing 
83 allows genotyping markers, such as SNPs, which may occur at high densities across the genome

84 (Davey et al. 2011; Twyford \& Ennos 2012; Savolainen et al. 2013). Importantly, whole genome

85 resequencing removes many of the ascertainment biases associated with SNP chips or other

86 genome reduction technologies. The dense marker saturation achieved through genome re-

87 sequencing is particularly useful for detecting the footprint of selection acting on specific

88 locations across the genome. For instance, selective sweeps, in which selection drives previously

89 rare alleles to fixation, also reduces diversity at neighbouring regions around the selected site

90 (Messer \& Petrov 2013). The signal left behind by selective sweeps can be detected by

91 comparing patterns of variation along the genome with the level expected under a null model.

92 Hard selective sweeps, where a single variant is driven to fixation, leave a characteristic

93 footprint in the genome, which can be identified using summary statistics such Tajima's $D$ or the

94 composite likelihood ratio (CLR) (Nielsen et al. 2005; Messer \& Petrov 2013). These statistics

95 may be particularly powerful to detect recent selective sweeps as linkage disequilibrium (LD)

96 between the selected site and the surrounding variation is expected to be highest immediately

97 following the fixation of the adaptive allele.

98 Genomic studies of native and introduced populations can uncover demographic, historical,

99 and selective processes by analysing the signature that these processes leave on genomic

100 variation. Here we use whole genome re-sequencing to assess the relationship between native

101 and introduced populations, and to uncover selective episodes in specific regions of the genome

102 of introduced populations. We study the yellow monkeyflower (Mimulus guttatus,

103 Phrymaceae), a species that has long been used as a model for ecological and evolutionary 
104 studies in its native range (Vickery 1959; Wu et al. 2008), and which has become naturalised in

105 Eastern North American, New Zealand, Iceland, the Faroe Islands, and Western Europe (van

106 Kleunen \& Fischer 2008; Murren et al. 2009; Tokarska-Guzik \& Dajdok 2010), becoming

107 particularly widespread in the United Kingdom (Vallejo-Marín \& Lye 2013). Mimulus guttatus is

108 ideally suited for studying the ecological genomics of non-native populations due to its recent

109 introduction and spread (<200 years), abundant information on the ecology and evolution of

110 native populations, and the availability of a full genome sequence, which provides a backbone

111 for analysing and interpreting patterns of genetic variation in introduced populations. The

112 relatively small genome of $M$. guttatus $(1 \mathrm{~N}=430 \mathrm{MB})$, makes this species a good candidate for

113 population genomic studies through re-sequencing, as multiple individuals can be analysed with

114 a relatively small budget. We analysed previously available and newly generated whole genome

115 sequence data for 12 native and 10 introduced British populations of $M$. guttatus, as well as five

116 additional related taxa ( $n=35$ Mimulus genomes in total). Our data set allowed us to address

117 three specific aims: (1) to determine the level of genome-wide diversity present in introduced

118 populations of $M$. guttatus in the United Kingdom; (2) to investigate the genetic relationships of

119 native and introduced populations; and (3) to search for evidence of hard selective sweeps in

120 introduced populations. 


\section{METHODS}

\section{Study system}

123 The Mimulus guttatus species complex includes a set of phenotypically variable, interfertile taxa

124 with a native range of distribution in Western North America from northern Mexico to Alaska

125 (Grant 1924; Wu et al. 2007). Within this complex, populations of M. guttatus Fischer ex DC.

126 (Grant 1924) show marked variation in characteristics including life history (annual/perennial)

127 (Hall \& Willis 2006; Lowry \& Willis 2010), mating system (Ritland 1990; Dole 1992), phenology

128 (Hall \& Willis 2006; Friedman \& Willis 2013), floral morphology (Fishman et al. 2002), edaphic

129 adaptations (e.g. tolerance to elevated concentrations of heavy metals or salt, Macnair \&

130 Watkins 1983; Lowry et al. 2008; Lowry et al. 2009), habitat preferences (Wu et al. 2008),

131 chromosome number (most populations are diploid: $2 n=2 x=28$, but tetraploids also occur in

132 the native range, Sweigart et al. 2008), and clonal growth (Dole 1992; van Kleunen 2007),

133 among others. This incredible diversity has led some taxonomists to subdivide M. guttatus into

134 numerous morphological species (e.g., Pennell 1951; Nesom 2012). Here we adhere to the

135 broader circumscription of M. guttatus Fischer ex DC. (Grant 1924; Wu et al. 2008).

136 Mimulus guttatus was introduced into the British Isles in 1812, and the first naturalised

137 populations were reported in England around 1830 (Roberts 1964; Parker 1975). In the UK, M.

138 guttatus is currently widespread and occurs in wet habitats along the banks of rivers and

139 streams, in ditches, marshy areas, and other wet places (Stace 2010; Vallejo-Marín \& Lye 2013).

140 It propagates via both seeds and clonally through lateral stems that root freely at the nodes. 
141 The source of the first naturalised populations of $M$. guttatus in the UK is unknown, but one of

142 the earliest specimens of this taxon to reach Europe was derived from material collected by

143 Langsdorff between 1806 and 1810 in the Aleutian Islands in Alaska, and transmitted to the

144 Botanic Gardens at Cambridge (Sims 1812; Pennell 1935, p. 116). The use of Mimulus spp. as a

145 horticultural species in Victorian England, as reflected by being readily available in seed

146 catalogues of the time (e.g., Gardeners' Chronicle 1852), raises the distinct possibility that $M$.

147 guttatus was introduced into the UK on repeated occasions and from multiple sources.

\section{Population sampling}

149 Analysing genomes across a wide geographic scale represents a trade-off between the numbers

150 of individuals vs. populations sampled. The goal of this study was to determine the introduction

151 history of Mimulus into the UK, the effects of the introduction on nucleotide diversity, and to

152 identify signals of selective sweeps that are common across the UK. To do this, we sought to

153 obtain samples from geographic disparate regions from across the UK. Obtaining geographically

154 distant samples increases the likelihood of identifying introductions from multiple different

155 donor populations. This sampling strategy also facilitated our goal of identifying selective

156 sweeps shared across the UK M. guttatus populations. Population specific selective sweeps

157 caused by local adaptation to narrow geographic and ecological niches in the UK are not

158 detected in our analyses and would require multiple individuals from the specific population of

159 interest. Previous molecular analyses of Mimulus guttatus have demonstrated that a scattered

160 sampling design, with 1 individual per population, is sufficient to capture regional

161 differentiation, and can avoid clustering biases resulting from sampling multiple individuals from 
162 fewer populations (Oneal et al. 2014). In total, we analysed genome data from 27 populations:

$16312 \mathrm{M}$. guttatus populations in the native range, 10 UK M. guttatus, and five outgroups. From

164 one of the native populations (Iron Mountain, IM) we sampled an additional 8 individuals, which

165 allowed us to explore the sensitivity of our findings to the particular individual sampled within a 166 population.

\section{Introduced populations}

168 We sampled 10 populations of $M$. guttatus spanning the range of distribution of this species in 169 the British Isles (Table 1; Fig. 1). The northernmost population came from the Shetland Islands 170 (QUA, $\mathrm{N} 60.105^{\circ} \mathrm{W} 1.227^{\circ}$ ) and the southernmost from Cornwall, England (CRO, N 50.163, $\mathrm{W}$

$1715.293^{\circ}$ ). A population from Northern Ireland was also included (VIC, N 54.763, W 7.454 ${ }^{\circ}$ ). Non-

172 native populations were collected from banks of canals, streams or rivers (HOU, CER, VIC, AYR,

173 DBL, TOM, and PAC), on roadside ditches (QUA), on waterlogged ground in an abandoned field

174 (CRO), or in a bog near a small stream (TRE). A single wild-collected individual per population

175 was randomly selected from each population for sequencing.

\section{Native range populations and outgroups}

177 We obtained sequence data from the Sequence Read Archive (SRA)

178 (http://www.ncbi.nlm.nih.gov/sra) from 12 native populations of $M$. guttatus, and five

179 outgroups within section Simiolus: M. nasutus (SF), M. cupriphillus (MCN), M. platycalyx (CVP),

180 M. micranthus (EBR), and M. dentilobus (DENT). The 12 native populations of $M$. guttatus

181 covered a linear transect of approximately $2800 \mathrm{~km}$ from Haida Gwaii (Queen Charlotte Islands),

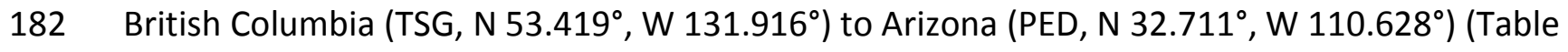


183 1). Populations in the native range occurred in a diversity of wet habitats including river and

184 stream banks, seeps, beach dunes, bogs, and springs. A single individual represented all but one

185 of the native populations. In the case of the Iron Mountain population (IM), we were able to

186 obtain data for nine separate individuals. Mean coverage per genotyped base per individual

187 ranged between $4-29 x$ with an average of $10 x$.

\section{DNA isolation and sequencing}

189 We collected leaf tissue of British M. guttatus individuals (one per population) in the field and

190 preserved it in re-sealable plastic bags with self-indicating silica gel (Fisher Scientific,

191 Loughborough, UK) at room temperature. This dry tissue was used for DNA extraction using the

192 Leaf MasterPure total DNA extraction kit (Cambio Ltd, Cambridge, UK). DNA libraries were

193 created and barcoded using the Nextera DNA sample preparation kit (Illumina, San Diego,

194 California), which uses a transposon based method to randomly tag DNA for multiplexed

195 sequencing. After library construction, an Agilent Bioanalyzer (Santa Clara, California) was used

196 to measure length distribution of library, and a fluorometer (Qubit 2.0, Life Technologies,

197 Paisley, UK) was used to measure concentration. Equimolar quantities of each library were

198 pooled and sequenced in an Illumina HiSeq 2500 rapid-run producing 150 base-pair paired-end

199 reads. Overall, we obtained raw coverage of $1.5-11 x$ per individual with an average of $5.7 x$.

200 Raw sequence data for UK Mimulus samples is deposited in the JGI SRA (SRA accession numbers

201 will be available upon acceptance of the manuscript). 


\section{Sequence data analysis}

\section{Genome alignment and SNP genotyping}

204 Raw reads were aligned to the Mimulus guttatus v2.0 genome available from Phytozome

205 (http://www.phytozome.net) using bowtie2 (Langmead \& Salzberg 2014) using -fast-local

206 allowing soft-clipping of poorly mapped read ends. After alignment, Picard tools

207 (http://picard.sourceforge.net) was used to remove duplicates, add read groups, and verify that

208 all mate information was accurate. After processing in Picard tools, the Genome Analysis Toolkit

209 (GATK, DePristo et al. 2011) was used to call genotypes using the 'Unified Genotyper'. Minimum

210 alignment quality was 25 and base quality was 25. Called genotypes were filtered to include

211 genotypes with a call quality threshold of Q30 or greater. Insertions, deletions, and

212 heterozygous sites were not included in subsequent analyses. Detailed command-line methods

213 can be found in the Supplementary Information. After all filtering, mean coverage per

214 genotyped base per individual for the 10 UK samples ranged from $1.7-5.8 x$ with an average of

$2153.5 x$. Of the $293 \mathrm{Mb}$ located on the main 14 genomic scaffolds (representing 14 linkage groups),

216 after all filtering, $71 \mathrm{Mb}$ were genotyped in at least one of the UK individuals. A total of 18.3,

217 18.5, and 8.9 Mb were genotyped in 8, 9, or 10 of the UK samples, respectively (Fig. S7).

\section{Measures of genetic diversity}

219 Nucleotide diversity at silent and non-silent sites was calculated using software described in

220 Zhang et al. (2006). Briefly, genomes for all sequenced lines were recalled using the genotype

221 data. Missing data was not imputed. Measurements of pairwise synonymous $\left(\pi_{\text {syn }}\right)$ and non- 
222 synonymous nucleotide diversity $\left(\pi_{\text {non-syn }}\right)$ were calculated through pairwise comparison of

223 coding sequences. Coding sequences were extracted from the recalled genomes using the gff3

224 gene annotation file available on phytozome.net. A Fisher p-value associated with each diversity

225 value and indicates the confidence of that particular value. We only considered $\pi_{\text {syn }}$ and $\pi_{\text {non-yn }}$

226 values for genes with a Fisher $p$-value $\leq 0.001$ and alignment length greater than 200 bases. In

227 addition to calculating nucleotide diversity at synonymous and non-synonymous sites, whole

228 genome alignments were used to calculate genome-wide nucleotide diversity $(\pi)$ in sliding

229 windows using VariScan (Hutter et al. 2006). Windows of 50,000 genotyped bases and

230 overlapping steps of 1000 bases were used.

\section{Genetic relationships between introduced and native M. guttatus}

232 In order to determine the genetic relationships between introduced and native populations we

233 conducted an analysis of genetic similarity using a random subset of $1,400,000$ SNPs. To create

234 this data set, we randomly selected 100,000 SNPs for each of the 14 major linkage groups

235 (chromosomes) that were genotyped in at least 30 individuals (out of 35). Our SNP data set is

236 therefore not subject to ascertainment bias arising from selecting, for example, only coding or

237 non-coding SNPs (Garvin et al. 2010). Instead the SNP dataset analysed here should represent a

238 snapshot of the total genetic diversity of each sample and be shaped by both neutral and non-

239 neutral processes (Helyar et al. 2011). Within each linkage group, neighbouring SNPs were

240 separated by 209 bp on average ( $209 \pm 3.34$; mean \pm SE). Each SNP was coded as "0" if it

241 matched the reference allele, and "1" for the alternative allele. In this analysis we included all

242 native and introduced individuals, and the five outgroups ( $n=35$ individuals). Multiple 
243 individuals from IM were included as a reference of the variation seen within a single

244 population.

245 We constructed a genetic distance matrix using $p$-distance (the proportion of nucleotide

246 sites that differ between a pair of sequences) from the binary SNP data using the package ape

247 (Paradis et al. 2004) in $R$ ver. 3.0.3 (R Development Core Team 2014). The combined distance

248 matrix was then used to estimate the relationships between all samples using a neighbour

249 joining (NJ) analysis in ape. Support for nodes in the NJ tree was calculated using 100 bootstrap

250 replicates. Trees were drawn using FigTree v. 1.4.0 (Rambaut 2014). The NJ distance-based

251 approach used here is appropriate for genome-wide analyses (e.g. Brandvain et al. 2014), as

252 maximum likelihood and Bayesian phylogenetic methods depend on specifying a mutational

253 model, which is not practical for genome-wide data. We also conducted a Principal Component

254 Analysis (PCA) using the function glPca in adegenet (Jombart \& Ahmed 2011). This analysis

255 provides an independent estimate of the relationships between native and introduced

256 populations, and can be used to compare with the results of the NJ analysis. For the PCA, we

257 selected only one individual for each of the 12 native and 10 introduced populations of $M$.

258 guttatus. The identity of the particular individual chosen from the IM population had no

259 qualitative effect on the relationships inferred from the PCA (Fig S8), and similarly, randomly

260 choosing one IM individual instead of nine for the NJ analysis did not change the tree topology

261 (data not shown). 


\section{Selective sweep analysis}

263 Regions in the genome showing the signature of selective sweeps were detected using the

264 parametric approach described in Nielsen et al. (2005), and implemented in the program

265 SweepFinder. This method compares the observed site frequency spectrum within local regions

266 in the genome (windows) against the background site frequency spectrum seen across the

267 entire genome (or linkage group), and calculates statistical departures from this background

268 expectation using a composite likelihood ratio (CLR). Importantly, the null hypothesis employed

269 by this method is derived from the background data itself and does not depend on specific

270 population genetic models or assumptions about demographic equilibrium (Nielsen et al. 2005),

271 which are unlikely to hold in recently introduced populations. SweepFinder is robust to models

272 that include population growth with recombination (Nielsen et al. 2005).

273 One potential issue with SweepFinder is that it is sensitive to SNP density (Nielsen et al.

274 2005). To account for both shared ancestral sweeps and artefacts due to genotype density, we

275 independently analysed the North American (NA) and UK data using the exact same criteria. Ten

276 samples from the North American populations (AHQ, BOG, DUN, IM, LMC, MAR, PED, SWB, TSG,

277 YJS) were chosen based on the results of the genome-wide relationship analysis. Next,

278 independently, for both the NA and UK datasets, we determined whether a given site was

279 polymorphic and asked how many individuals were genotyped at that particular site. Using this

280 information, we choose sites that were genotyped in at least 8 individuals (of the 10 total) in

281 both the UK and NA samples and were polymorphic in at least one of these populations. Thus,

282 we ended up with a dataset that included the exact same number of sites from the exact same 
283 genomic locations. Next, we calculated genome-wide SFS for each dataset (UK and NA). Each

284 chromosome was divided into 5000 bins and the SFS within each bin was compared to the

285 genome-wide SFS to look for signals of a selective sweep using the parametric approach

286 described (Nielsen et al. 2005) and implemented in SweepFinder.

287 After running SweepFinder, we independently plotted the genome-wide CLR distribution

288 for UK and NA samples. Within the NA samples, all genomic locations with CLR scores above the

289 median value were marked for masking. Liberal masking based on the NA analyses removes

290 hard sweeps that occurred in the last common ancestor, and removes artefacts due to variable

291 genotype density. The NA SweepFinder results were used to mask the UK genome SweepFinder

292 results. Only genomic positions that survived masking were considered in further analyses.

293 Within the UK, the top 1\% CLR outliers were identified as regions that have possibly experienced

294 a hard sweep and subjected to further investigation. Gene coordinates are available in the gff3

295 gene annotation on Phytozome and genes with positions at least partially overlapping the swept

296 regions were extracted for further analyses.

\section{RESULTS}

\section{Nucleotide diversity in M. guttatus}

299 Overall genome-wide nucleotide diversity in the UK was $\pi=0.015$ (Fig. S1). Figures S2 and S3

300 show patterns of nucleotide diversity across the genome for both native and introduced

301 populations. For genes, within UK samples, diversity at silent sites was $\pi_{\text {syn }}=0.0325$ while non-

302 synonymous diversity was $\pi_{\text {non-syn }}=0.0035$ (Fig. S4). Within the native North American 
303 populations, nucleotide diversity was calculated through comparisons of 10 individuals (same 10

304 individuals used as the NA samples in sweep analyses). Genome-wide diversity within the NA

305 samples is $\pi=0.031$ (Fig. S1). Synonymous diversity within NA is $\pi_{\text {syn }}=0.0610$ while non-

306 synonymous diversity is $\pi_{\text {non-syn }}=0.0075$ (Fig. S4). Comparing NA and UK nucleotide diversity

307 indicates an overall reduction in the introduced populations of approximately $50 \%$.

\section{Genetic relationships of native and introduced populations}

309 The relationships between 22 native and introduced populations of Mimulus guttatus, and five

310 outgroups based on the genetic distance of $1,400,000$ SNPs distributed across the genome is

311 shown in Fig. 2. All the population level nodes in this NJ tree had a bootstrap support of $100 \%$.

312 The NJ tree shows that all 10 UK populations form a single well-supported clade (Fig. 2). The UK

313 clade is most closely related to the native TSG population, a coastal perennial M. guttatus from

314 Graham Island (Queen Charlotte Islands) in British Columbia (Lowry \& Willis 2010). The UK and

315 TSG samples form part of a clade of populations located north of the $\mathrm{N} 40^{\circ}$ parallel, and which

316 includes other inland perennial (BOG and YJS), and annual populations (AHQ, IM, and MAR)

317 (Figs. 1 and 2; Table 1). The NJ tree shows a second clade composed mainly of more southern

318 populations, and which includes inland plants (LMC, REM), coastal perennials (SWB, DUN), as

319 well as two annual outgroups (CVP, M. platycalyx; EBR, M. micranthus). The DUN population is

320 the only one in this group located north of the $\mathrm{N} 40^{\circ}$ parallel (Fig. 1). Finally, the NJ tree shows a

321 third clade including three of outgroups (MCN, M. cupriphilus; SF, M. nasutus; DENT, $M$.

322 dentilobus), as well as the two most southern populations of M. guttatus, MED, an annual

323 inland population, and PED, an inland perennial from Arizona. Our results indicate that native 
324 M. guttatus is separated into two main clades corresponding mostly to geographic location

325 (North and South groups), and not to different life histories (annual/perennial) or habitat types

326 (coastal/inland), as has been recently described by Brandvain et al. (2014). Finally, our NJ

327 analysis also indicates that $M$. cupriphilus and $M$. platycalyx are nested within broadly

328 circumscribed M. guttatus (Fig. 2).

329 The results of the PCA show clear support for a close relationship between all UK

330 samples, and also indicate that the most genetically similar native population sampled here is

331 the coastal perennial TSG (Fig. 3). The first principal component separates the North and South

332 groups of native M. guttatus, with DUN partly overlapping with the North group. The second

333 principal component separates the UK samples from most of the other northern accessions (Fig.

334 3). Together, the NJ and PCA show a common ancestry of British Mimulus guttatus, and its 335 association with northern, native populations.

\section{Evidence of selection in introduced populations}

337 Our analysis of selective sweeps in native and introduced populations identified several genomic

338 regions displaying changes in the site frequency spectrum (measured using the CLR statistic),

339 consistent with the signatures of positive selection acting in these regions (Fig. 4; results for all

340 linkage groups are shown in Fig. S5). The comparison of high CLR regions in the separate

341 analyses conducted in NA and UK samples, allowed us to detect selective sweeps shared by

342 both native and introduced populations. By masking these high CLR sites in NA, we located

343 genomic regions that are candidates for selective sweeps occurring after the separation of the

344 clade leading to the UK populations, including potentially unsampled North American donor 
345 populations. Moreover, the masking also accounted for possible regions with high CLR scores

346 that were simply due to low genotyped SNP density. Our analysis revealed selective sweeps on

347 five of the 14 linkage groups in the UK, which are not shared with NA samples (Fig. 4, Table 1).

348 Regions with high CLR scores showed significantly reduced overall diversity: Diversity within

349 sweeps was $\pi=0.0076$, half that of nucleotide diversity outside sweeps $\pi=0.0152 .(p \leq 0.0001$;

350 Figs. S6).

351 We identified a total of 299 genes located under the candidate region for selective

352 sweeps within the UK clade (Table S1). Synonymous diversity for genes within sweeps was

353 significantly lower than silent site diversity outside sweeps of ( $\pi_{\text {syn }}=0.0147 \mathrm{vs.} \pi_{\text {syn }}=0.0323 ; p \leq$

3540.0001 ) (Fig. S6). Within sweeps, 28 genes had $\pi_{\text {syn }}<0.01$ (Table S2) and only two genes under

355 sweeps had silent site diversity $\left(\pi_{\text {syn }}\right)$ above the genome-wide mean. Taking advantage of the

356 annotated genome of $M$. guttatus, we recorded genes located within the swept regions, which

357 included genes involved in flowering time, abiotic stress response including nutrient transport

358 and freezer tolerance, and biotic stress responses (Table S1).

\section{DISCUSSION}

360 Our study represents the first genome resequencing study of native and introduced populations

361 of Mimulus guttatus. By analysing whole genome sequences of 35 individuals from 22

362 populations we demonstrated that introduced plants in the UK are characterized by a $\sim 50 \%$

363 reduction in synonymous $\left(\pi_{\text {syn }}\right)$ genetic diversity, and that UK populations form a single clade,

364 relative to the North American samples included here, suggesting a common origin for non- 
365 native populations. Our analysis revealed changes in the site frequency spectrum at multiple

366 locations across the genome, consistent with selective sweeps, some of which were restricted

367 to UK samples. The reduction of both synonymous and non-synonymous nucleotide diversity in

368 genes located within sweep regions, compared to genes outside of these sweeps, was

369 consistent with the expected loss of genetic diversity in regions linked to selected loci. Future

370 studies are required to assess whether selection is indeed responsible for the observed patterns

371 of variation in the sweep candidate regions, as well as to determine if such selection acted

372 before or after the introduction of M. guttatus into the UK. This study illustrates the potential of

373 whole-genome sequencing studies to provide the initial steps for understanding the genomic

374 consequences of invasion and rapid adaptation to new environments.

\section{Origin and diversity of Mimulus guttatus populations in the UK}

376 Determining the geographic origin of introduced populations provides a reference point for

377 studies of the potential ecological and evolutionary changes occurring during the colonization

378 and establishment phases of biological invasions (Milne \& Abbott 2000). Our sample of North

379 American populations includes a large part of the native range of $M$. guttatus (Fig. 1), but

380 admittedly still represents a small fraction of populations from this widely distributed taxon

381 (Grant 1924). However, we were able to include populations with different life histories,

382 morphologies, and habitat preferences (Table 1), including different ecological and

383 morphological groups (Lowry et al. 2008; Lowry \& Willis 2010).

384 Our analysis of genome-wide polymorphism revealed two main clades of M. guttatus in

385 the native range, which broadly correspond to their geographic origin (North and South groups; 
386 Brandvain et al. 2014). An exception to the geographic arrangement of these two groups of $M$.

387 guttatus is the DUN population. Although geographically located in the northern range (Fig. 1),

388 DUN is nested within the southern group (Fig. 2), and may represent a secondary dispersal or

389 reflect an introgression event between these two groups (Brandvain et al. 2014). Interestingly,

390 the North and South clades of M. guttatus include populations with contrasting habitats,

391 morphologies, and life histories (Table 1), suggesting that taxonomic groupings based on

392 general morphological and ecological attributes are unlikely to correspond to monophyletic

393 clades (Nesom 2012). At the same time, the polyphyletic nature of the M. guttatus species

394 complex is reflected in our results by the fact that a M. guttatus population (MED) is nested

395 within outgroup taxa (SF: M. nasutus, and MCN: M. cupriphilus; Fig. 2), while M. platycalyx (CVP)

396 and M. micranthus (EBR) fall within M. guttatus populations. Elucidating the phylogenetic

397 relationships within the $M$. guttatus species complex has proven challenging (Beardsley et al.

398 2003; Beardsley et al. 2004), but the use of genome-wide sequences in a phylogenetic context

399 (Wagner et al. 2013) could provide a tool to establish the genetic relationships among

400 populations of this interfertile group.

401 The genetic structure observed in indigenous populations, allowed us to determine with

402 confidence that introduced populations in the UK are most genetically similar to populations

403 from the northern end of the native distribution. In particular, our results indicate that UK

404 samples are most genetically similar to the coastal perennial population of TSG (Figs. 2 and 3).

405 However, without additional sampling, the exact source for introduced populations in the UK

406 remains unknown. The genetic similarity within UK populations, which fall within a single clade 
407 (Fig. 2), suggests that this part of the introduced range has been established either via a single

408 introduction event or, perhaps more likely, via multiple introductions from closely related native

409 populations. In order to determine the origin and number of introductions of UK M. guttatus

410 with more accuracy, it will be necessary to conduct further sampling in the Alaskan end of the

411 distribution, since historical records point to this region as a potential source for the first

412 specimens of this taxon in Europe (Sims 1812; Pennell 1935, p. 116).

413 Despite a 50\% reduction in nucleotide diversity $(\pi)$ in non-native $M$. guttatus, UK

414 populations still harbour a significant amount of diversity among populations. In particular, the

415 estimate of nucleotide diversity at synonymous sites in UK populations $\left(\pi_{\text {syn }}=0.0325\right)$ is above

416 the median estimate of neutral nucleotide diversity for outcrossing flowering plants $(\pi=$

$4170.0148)$, and much higher than the estimate for selfing taxa $(\pi=0.0035)$ (Leffler et al. 2012). The

418 diversity observed in UK populations suggests that the bottleneck experienced by M. guttatus

419 during invasion was weak enough to permit the maintenance of a significant amount of

420 nucleotide diversity. In general, introduced populations tend to show reduced genetic diversity

421 compared to native ones, but phenomena including large initial propagule numbers, multiple

422 introductions, and admixture can result in equal or higher levels of genetic variation (Dlugosch

423 \& Parker 2008). The existence of non-synonymous variation in UK M. guttatus $\left(\pi_{\text {non-syn }}=0.0035\right)$

424 is potentially important for naturalisation and spread in the new range, as introduced

425 populations may be able to respond to new selective pressures from standing genetic variation,

426 and are not necessarily limited by mutation rate (Prentis et al. 2008). Adaptation from standing 
427 genetic variation is particularly important for invasive species as it may allow responding more

428 rapidly to novel selective pressures (Barrett \& Schluter 2008).

\section{Detecting selection in non-equilibrium populations}

430 Our study uncovered several areas of the genome that bear the signature of positive selection.

431 The signal left by selective sweeps include increased frequency of previously rare derived

432 alleles, reduction of variation in linked sites, and increase in local linkage disequilibrium (Smith

433 \& Haigh 1974; Barton 1998). However, past demographic changes can confound the pattern of a

434 selective sweep (Barton 1998; Barton \& Etheridge 2004). This is particularly the case in

435 populations that have experienced a bottleneck and subsequent population growth with

436 recombination (Barton \& Etheridge 2004; Nielsen et al. 2005). Furthermore, recombination

437 between lineages that either escape or not the population bottleneck will result in a

438 combination of short and long coalescent branches creating a sweep like pattern in the SFS

439 (Pavlidis et al. 2010). Thus, inferences of selection based on genome scans in non-equilibrium

440 populations must be done with caution.

441 The implementation that we used to detect the signature of positive selection

442 (SweepFinder), is relatively robust to the effects of bottlenecks and population expansion, and is

443 particularly powerful to detect recent selective sweeps (Nielsen et al. 2005; Pavlidis et al. 2010).

444 Recent studies have shown that SweepFinder performs better than other tests, such as the $\omega$ -

445 statistic, in non-equilibrium populations (Pavlidis et al. 2010). We consider that the very recent

446 introduction of $M$. guttatus into the UK, relatively weak population bottleneck, and lack of

447 within-UK population structure, make SweepFinder an appropriate method for detecting recent 
448 and strong sweeps in the introduced range. Moreover, the independently analysed NA data

449 using the exact same SNP sampling strategy allowed us to mask shared sweeps and eliminate

450 false positives due solely to SNP sampling and variable site density. Therefore, we consider that

451 the genomic regions identified here are strong candidates for selective sweeps in the lineage

452 leading to UK populations. Nevertheless, it is important to recognise that we cannot currently

453 determine whether the selection events happened in an ancestral (unsampled) native

454 population or after the dispersal of M. guttatus to the UK. Establishing the timing of the

455 potential selective event is essential to determine if introduced populations can exploit novel

456 environments through (pre-)adaptations brought in from the native range, or whether adaptive

457 evolution occurs subsequent to dispersal during the establishment and spread phases of a

458 biological invasion (Maron et al. 2004; Colautti et al. 2009).

\section{Genes within swept regions}

460 The potential selective sweeps we detected in five M. guttatus chromosomes include

461 approximately 300 genes. As predicted for selective sweeps, we found reduced diversity in both

462 coding and non-coding genic regions under these sweeps (Fig S6). While it is possible to identify

463 candidate regions for selective sweeps and to determine the genes located under these sweeps,

464 it is not possible to know without direct testing which genes were the actual targets of

465 selection. However, the selective sweeps identified here contain genes involved in flowering

466 time, nutrient stress, and biotic stress (Table S2), and could be involved in adaptation to

467 different day lengths, soil types, novel pathogens, and general responses to stress (e.g., Hodgins

468 et al. 2012). 
Of particular interest is the identification of selective sweeps in linkage group 8 (LG8).

470 The selective sweeps at positions $2 \mathrm{Mbp}$ (two million base pairs) and $5 \mathrm{Mbp}$ of LG8 are

471 exceptionally wide, consistent with very strong selection pulling a large haplotype block to high

472 frequency very quickly giving very little time for recombination to break up linked sites. These

473 regions of LG8 are gene rich suggesting that the width of the peak is not an artefact of reduced

474 recombination associated with repetitive regions (Hellsten et al. 2013). Instead, these selective

475 sweeps are located near or at a known inversion region of approximately 6Mb in length (Oneal

476 et al. 2014). This inversion (DIV1), is polymorphic in the native range, and is associated with a

477 number of morphological and life-history differences between annual and perennial ecotypes

478 (Lowry and Willis 2010). Therefore this region is a good candidate for bearing adaptive variation

479 that could be selected for in the lineage leading to the introduced populations. Mapping

480 experiments in M. guttatus have demonstrated that a large region on LG8 is involved in critical

481 photoperiod to flower (Friedman \& Willis 2013). The selective sweep we identified on LG8 is

482 located near (within 200,000 base pairs) one of the major QTLs for critical photoperiod

483 identified in Friedman and Willis' study. Flowering time is a crucial component of fitness in

484 seasonal environments, and therefore it is expected to be under selection in the introduced

485 range. Studies of invasive species have often demonstrated the potential for rapid evolution of

486 phenology in the introduced range (Maron et al. 2004; Colautti et al. 2009). The geographic

487 distribution of introduced populations at high latitudes (approximately between $50^{\circ} \mathrm{N}$ and $60^{\circ} \mathrm{N}$

488 in the UK), suggests that these populations experience day length conditions similar to the

489 northern end of the distribution of M. guttatus in North America. It would be of interest to 
490 determine if genes involved in the control of flowering under long days are under selection in

491 northern indigenous or in introduced populations. One such candidate is Migut.D02071, a

492 phytochrome-associated protein phosphatase gene located in one of the selective sweep

493 regions in LG4 (Table S2). In Arabidopsis thaliana, a similar gene (ATFYPP3) participates in the

494 regulation of flowering time in long days (www.string-db.org). Preliminary data suggests that UK

495 populations require long days (16hr) to flower (Vallejo-Marín, unpublished). Future studies

496 could address whether flowering time has indeed played a role in the establishment of

497 introduced populations in high latitudes.

498 To conclude, our results demonstrate the enormous potential for whole-genome

499 sequencing studies to contribute to the study of non-native populations. With a modest

500 sequencing effort we were able to quickly obtain previously unavailable information on the

501 origin and diversity of introduced populations of M. guttatus, as well as on the genomic

502 consequences of biological introductions, including identifying potential regions under

503 selection. As whole genome reference data becomes available for other non-model organisms,

504 resequencing studies are likely to be increasingly used to study the history and consequences of

505 biological invasions, and to establish the contribution of adaptive processes to shaping the

506 genomes of rapidly evolving populations.

\section{ACKNOWLEDGMENTS}

508 We thank J. H. Willis for his support and advice, the Mimulus community for providing

509 information and sharing unpublished data, and to A. Twyford, J. Friedman, V. Sork and three 
510 anonymous reviewers for comments on a previous version of the manuscript. This work was

511 supported by a US National Science Foundation - National Plant Genome Initiative postdoctoral

512 fellowship to JP (NSF, 1202778), and a UK Natural Environment Research Council grant (NERC,

513 NE/J012645/1) and a Carnegie Trust Travel grant to MVM.

\section{REFERENCES}

515 Baker HG, Stebbins GL, eds (1965) The Genetics of Colonizing Species Academic Press, Silomar.

516 Barrett RDH, Schluter D (2008) Adaptation from standing genetic variation. Trends in Ecology \&

517 Evolution, 23, 38-44.

518 Barton NH (1998) The effect of hitch-hiking on neutral genealogies. Genetical Research, 72, 123-

519133.

520 Barton NH, Etheridge AM (2004) The effect of selection on genealogies. Genetics, 166, 1115-

$521 \quad 1131$.

522 Beardsley PM, Schoenig SE, Whittall JB, Olmstead RG (2004) Patterns of evolution in Western

523 North American Mimulus (Phrymaceae). American Journal of Botany, 91, 474-489.

524 Beardsley PM, Yen A, Olmstead RG (2003) AFLP phylogeny of Mimulus section Erythranthe and

525 the evolution of hummingbird pollination. Evolution, 57, 1397-1410. 
526 Brandvain Y, Kenney AM, Flagel L, Coop G, Sweigart AL (2014) Speciation and introgression

527 between Mimulus nasutus and Mimulus guttatus. PLOS Genetics, 10, e1004410.

528 Colautti RI, Maron JL, Barrett SCH (2009) Common garden comparisons of native and introduced

529 plant populations: latitudinal clines can obscure evolutionary inferences. Evolutionary

$530 \quad$ Applications, 2, 187-199.

531 Cox GW (2004) Alien Species and Evolution Island Press, Washington.

532 Davey JW, Hohenlohe PA, Etter PD, Boone JQ, Catchen JM, Blaxter ML (2011) Genome-wide 533 genetic marker discovery and genotyping using next-generation sequencing. Nature 534 Reviews Genetics, 12, 499-510.

535 DePristo MA, Banks E, Poplin R, et al (2011) A framework for variation discovery and genotyping 536 using next-generation DNA sequencing data. Nature Genetics, 43, 491-498.

537 Dlugosch KM, Parker IM (2008) Founding events in species invasions: genetic variation, adaptive 538 evolution, and the role of multiple introductions. Molecular Ecology, 17, 431-449.

539 Dlugosch KM, Lai Z, Bonin A, Hierro J, Rieseberg LH (2013) Allele identification for

$540 \quad$ transcriptome-based population genomics in the invasive plant Centaurea solstitialis. G3-

541 Genes Genomes Genetics, 3, 359-367.

542 Dole JA (1992) Reproductive assurance mechanisms in 3 taxa of the Mimulus guttatus complex 543 (Schrophulariaceae). American Journal of Botany, 79, 650-659. 
544 Ellegren H (2014) Genome sequencing and population genomics in non-model organisms.

$545 \quad$ Trends in Ecology \& Evolution, 29, 51-63.

546 Fishman L, Kelly AJ, Willis JH (2002) Minor quantitative trait loci underlie floral traits associated

547 with mating system divergence in Mimulus. Evolution, 56, 2138-2155.

548 Friedman J, Willis JH (2013) Major QTLs for critical photoperiod and vernalization underlie 549 extensive variation in flowering in the Mimulus guttatus species complex. New Phytologist, $550 \quad 199,571-583$.

551 Gardeners' Chronicle (1852) The Gardeners' Chronicle and Agricultural Gazette Bradbury and $552 \quad$ Evans, London.

553 Garvin MR, Saitoh K, Gharrett AJ (2010) Application of single nucleotide polymorphisms to non554 model species: a technical review. Molecular Ecology Resources, 10, 915-934.

555 Grant AL (1924) A monograph of the genus Mimulus. Annals of the Missouri Botanical Garden, $556 \quad 11,99-380$.

557 Hall MC, Willis JH (2006) Divergent selection on flowering time contributes to local adaptation in $558 \quad$ Mimulus guttatus populations. Evolution, 60, 2466-2477.

559 Hellsten U, Wright KM, Jenkins J, et al (2013) Fine-scale variation in meiotic recombination in 560 Mimulus inferred from population shotgun sequencing. Proceedings of the National $561 \quad$ Academy of Sciences of the United States of America, 110, 19478-19482. 
562 Helyar SJ, Hemmer-Hansen J, Bekkevold D, et al (2011) Application of SNPs for population 563 genetics of nonmodel organisms: new opportunities and challenges. Molecular Ecology

$564 \quad$ Resources, 11, 123-136.

565 Hodgins KA, Lai Z, Kurkowski K, Huang J, Rieseberg LH (2012) The molecular basis of

566 invasiveness: differences in gene expression of native and introduced common ragweed

567 (Ambrosia artemisiifolia) in stressful and benign environments. Molecular Ecology, 22,

$568 \quad 2496-2510$.

569 Hulme PE (2009) Trade, transport and trouble: managing invasive species pathways in an era of $570 \quad$ globalization. Journal of Applied Ecology, 46, 10-18.

571 Hutter S, Vilella AJ, Rozas J (2006) Genome-wide DNA polymorphism analyses using VariScan.

572 BMC bioinformatics, 7, 409.

573 Jahodová Š, Trybush S, Pyšek P, Wade M, Karp A (2007) Invasive species of Heracleum in

$574 \quad$ Europe: an insight into genetic relationships and invasion history. Diversity and

575 Distributions, 13, 99-114.

576 Jombart T, Ahmed I (2011) adegenet 1.3-1: New tools for the analysis of genome-wide SNP data.

577 Bioinformatics, 27, 3070-3071. 
578 Lachmuth S, Durka W, Schurr FM (2010) The making of a rapid plant invader: genetic diversity

579 and differentiation in the native and invaded range of Senecio inaequidens. Molecular

$580 \quad$ Ecology, 19, 3952-3967.

581 Langmead B, Salzberg SL (2014) Bowtie 2.2.1. Ultrafast and memory-efficient alignment of short

582 DNA sequences to the human genome. Nature Methods, 9, 357-359.

583 Lee CE (2002) Evolutionary genetics of invasive species. Trends in Ecology \& Evolution, 17, 386-

$584 \quad 391$.

585 Leffler EM, Bullaughey K, Matute DR, Meyer, WK, Ségurel L, Venkat A, Andolfatto P, Przeworski

$586 \quad$ M (2012) Revisiting and old riddle: What determines genetic diversity levels within species?

$587 \quad$ PLOS Biology, 10, e1001388.

588 Liu H, Pemberton RW (2009) Solitary invasive orchid bee outperforms co-occurring native bees 589 to promote fruit set of an invasive Solanum. Oecologia, 159, 515-525.

590 Lowry DB, Rockwood RC, Willis JH (2008) Ecological reproductive isolation of coast and inland $591 \quad$ races of Mimulus guttatus. Evolution, 62, 2196-2214.

592 Lowry DB, Hall MC, Salt DE, Willis JH (2009) Genetic and physiological basis of adaptive salt 593 tolerance divergence between coastal and inland Mimulus guttatus. New Phytologist, 183, $594 \quad 776-788$. 
595 Lowry DB, Rockwood RC, Willis JH (2008) Ecological reproductive isolation of coast and inland 596 races of Mimulus guttatus. Evolution, 62, 2196-2214.

597 Lowry DB, Willis JH (2010) A widespread chromosomal inversion polymorphism contributes to a 598 major life-history transition, local adaptation, and reproductive isolation. PLoS Biology, 8, 599 e1000500.

600 Macnair MR, Watkins AD (1983) The fitness of the copper tolerance gene of Mimulus guttatus in 601 uncontaminated soil. New Phytologist, 95, 133-137.

602 Maron JL, Vila M, Bommarco R, Elmendorf S, Beardsley P (2004) Rapid evolution of an invasive 603 plant. Ecological Monographs, 74, 261-280.

604 Messer PW, Petrov DA (2013) Population genomics of rapid adaptation by soft selective sweeps. 605 Trends in Ecology \& Evolution, 28, 659-669.

606 Milne RI, Abbott RJ (2000) Origin and evolution of invasive naturalized material of 607 Rhododendron ponticum L. in the British Isles. Molecular Ecology, 9, 541-556.

608 Murren CJ, Chang CC, Dudash MR (2009) Patterns of selection of two North American native and 609 nonnative populations of monkeyflower (Phrymaceae). New Phytologist, 183, 691-701.

610 Nesom G (2012) Taxonomy of Erythranthe Sect. Simiola (Phrymaceae) in the USA and Mexico.

611 Phytoneuron, 40, 1-123. 
612 Ness RW, Siol M, Barrett SCH (2012) Genomic consequences of transitions from cross- to self-

613 fertilization on the efficacy of selection in three independently derived selfing plants. BMC

614 Genomics, 13, 611.

615 Nielsen R, Williamson S, Kim Y, Hubisz MJ, Clark AG, Bustamante C (2005) Genomic scans for 616 selective sweeps using SNP data. Genome Research, 15, 1566-1575.

617 Oneal E, Lowry DB, Wright KM, Zhu Z, Willis JH (2014) Divergent population structure and 618 climate associations of a chromosomal inversion polymorphism across the Mimulus 619 guttatus species complex. Molecular Ecology, 23, 2844-2860.

620 Paradis E, Claude J, Strimmer K (2004) APE: Analyses of phylogenetics and evolution in R 621 language. Bioinformatics, 20, 289-290.

622 Parker PF (1975) Mimulus in Great Britain: A cytotaxonomic note. New Phytologist, 74, 155-160.

623 Pavlidis P, Jensen JD, Stephan W (2010) Searching for footprints of positive selection in whole624 genome SNP data from nonequilibrium populations. Genetics, 185, 907-922.

625 Pennell FW (1935) The Scrophulariaceae of eastern temperate North America. The Academy of $626 \quad$ Natural Sciences of Philadelphia, 1, 1-650.

627 Pennell F (1951) Mimulus. In: Illustrated Flora of the Pacific States (eds. Abrams LR, Ferris RS), 628 vol. 3 edn, pp. 688-731 Stanford University Press. 
629 Phillips BL, Shine R (2006) An invasive species induces rapid adaptive change in a native

630 predator: cane toads and black snakes in Australia. Proceedings of the Royal Society B-

631 Biological Sciences, 273, 1545-1550.

632 Pimentel D, ed (2002) Biological Invasions: Economic and Environmental Costs of Alien Plant, 633 Animal, and Microbe Species CRC Press, Boca Raton, Florida.

634 Prentis PJ, Wilson JRU, Dormontt EE, Richardson DM, Lowe AJ (2008) Adaptive evolution in 635 invasive species. Trends in Plant Science, 13, 288-294.

636 Prentis PJ, Woolfit M, Thomas-Hall SR, et al (2010) Massively parallel sequencing and analysis of 637 expressed sequence tags in a successful invasive plant. Annals of Botany, 106, 1009-1017.

638 Preston CD, Pearman DA, Dines TD, eds (2002) New Atlas of the British and Irish Flora Oxford $639 \quad$ University Press, Oxford.

640 R Development Core Team (2014) R. A language and environment for statistical computing. R 641 Foundation for Statistical Computing, Vienna, Austria. URL http://www.R-project.org/. ver. $642 \quad 3.0 .3$.

643 Rambaut A (2014) FigTree version 1.4.0. http://tree.bio.ed.ac.uk/software/figtree/[accessed $644 \quad$ March 12, 2014].

645 Ricciardi A, Hoopes MF, Marchetti MP, Lockwood JL (2013) Progress toward understanding the 646 ecological impacts of nonnative species. Ecological Monographs, 83, 263-282. 
647 Ritland K (1990) Inferences about inbreeding depression based on changes of the inbreeding 648 coefficient. Evolution, 44, 1230-1241.

649 Roberts RH (1964) Mimulus hybrids in Britain. Watsonia, 6, 70-75.

650 Roda F, Ambrose L, Walter GM, et al (2013) Genomic evidence for the parallel evolution of 651 coastal forms in the Senecio lautus complex. Molecular Ecology, 22, 2941-2952.

652 Savolainen O, Lascoux M, Merila J (2013) Ecological genomics of local adaptation. Nature 653 Reviews Genetics, 14, 807-820.

654 Sax DF, Stachowicz JJ, Brown JH, et al (2007) Ecological and evolutionary insights from species 655 invasions. Trends in Ecology \& Evolution, 22, 465-471.

656 Silverside AJ (1990) A new binomial in Mimulus. Watsonia, 18, 210-212.

657 Sims J (1812) Curtis's Botanical Magazine. Flower-Garden Displayed. Vol. 35. Sherwood, Neeley 658 \& Jones, London.

659 Siol M, Wright SI, Barrett SCH (2010) The population genomics of plant adaptation. New $660 \quad$ Phytologist, 188, 313-332.

661 Smith JM, Haigh J (1974) The hitchhiking effect of a favorable gene. Genetical Research, 23, 23662 35. 
663 Stace C (2010) New Flora of the British Isles, Third Edition edn. Cambridge University Press, 664 Cambridge.

665 Sweigart AL, Martin NH, Willis JH (2008) Patterns of nucleotide variation and reproductive 666 isolation between a Mimulus allotetraploid and its progenitor species. Molecular Ecology, $667 \quad 17,2089-2100$.

668 Tarnowska K, Daguin-Thiebaut C, Pain-Devin S, Viard F (2013) Nuclear and mitochondrial genetic 669 variability of an old invader, Dreissena polymorpha (Bivalvia), in French river basins. 670 Biological Invasions, 15, 2547-2561.

671 Tokarska-Guzik B, Dajdok Z (2010) NOBANIS. Invasive Alien Species Fact Sheet: Mimulus 672 guttatus. Online Database of the European Network on Invasive Alien Species - NOBANIS 673 www.nobanis.org, Date of access 1/03/2014.

674 Truscott AM, Soulsby C, Palmer SCF, Newell L, Hulme PE (2006) The dispersal characteristics of 675 the invasive plant Mimulus guttatus and the ecological significance of increased occurrence 676 of high-flow events. Journal of Ecology, 94, 1080-1091.

677 Twyford AD, Ennos RA (2012) Next-generation sequencing as a tool for plant ecology and 678 evolution. Plant Ecology \& Diversity, 5, 411-413.

679 Vallejo-Marín M, Lye GC (2013) Hybridisation and genetic diversity in introduced Mimulus 680 (Phrymaceae). Heredity, 110, 111-122. 
681 van Kleunen M (2007) Adaptive genetic differentiation in life-history traits between populations 682 of Mimulus guttatus with annual and perennial life-cycles. Evolutionary Ecology, 21, 185683199.

684 van Kleunen M, Fischer M (2008) Adaptive rather than non-adaptive evolution of Mimulus 685 guttatus in its invasive range. Basic and Applied Ecology, 9, 213-223.

686 Vickery RK (1959) Barriers to gene exchange within Mimulus guttatus (Scrophulariaceae).

687 Evolution, 13, 300-310.

688 Vila M, Espinar JL, Hejda M, et al (2011) Ecological impacts of invasive alien plants: a meta689 analysis of their effects on species, communities and ecosystems. Ecology Letters, 14, 702690708.

691 Vos P, Hogers R, Bleeker M, et al (1995) AFLP: a new technique for DNA fingerprinting. Nucleic 692 acids research, 23, 4407-4414.

693 Wagner CE, Keller I, Wittwer S, et al (2013) Genome-wide RAD sequence data provide 694 unprecedented resolution of species boundaries and relationships in the Lake Victoria 695 cichlid adaptive radiation. Molecular Ecology, 22, 787-798.

696 Williams F, Eschen R, Harris A, et al (2010) The economic cost of invasive non-native species on 697 Great Britain. CABI report, 198pp. 
698 Wu CA, Lowry DB, Cooley AM, Wright KM, Lee YW, Willis JH (2007) Mimulus is an emerging 699 model system for the integration of ecological and genomic studies. Heredity, 100, 220-230.

700 Zhang Z, Li J, Zhao X, Wang J, Wong GK, Yu J (2006) KaKs_calculator: Calculating Ka and Ks

701 through model selection and model averaging. Genomics Proteomics \& Bioinformatics, 4,

$702 \quad 259-263$. 


\section{Data Accessibility}

704 DNA sequences: NCBI SRA (individual population codes in parentheses): SRR1462346 (10-AYR-10), SRR1475232 (10-CER-10),

705 SRR1475385 (10-DBL-20), SRR1481643 (10-HOU-17), SRR1481644 (10-QUA-47), SRR1482404 (10-TOM-23), SRR1482405 (12-

706 CRO-5), SRR1482406 (12-PAC-39), SRR1482407 (12-VIC-18), SRR1482409 (12-TRE-17).

707 SNP Genotype data: Dryad doi:10.5061/dryad.3gp32

\section{Author Contributions}

709 MVM and JP designed the research. MVM made the field surveys and collected the samples. JP and MVM organized laboratory

710 work. JP generated the genomic data and conducted the bioinformatic analyses. JP and MVM analysed the genomic data. MVM

711 and JP wrote the manuscript. 


\section{TABLES}

713 Table 1. Populations sampled for genome resequencing of Mimulus guttatus and related taxa. A single individual was sequenced per population, except for IM, where sequence data was available for nine individuals. Life history and, for native populations, their classification as coastal or inland, is provided for each population when available (Lowry et al. 2008; Lowry \&

716 Willis 2010).

\begin{tabular}{|c|c|c|c|c|c|}
\hline Population Taxon & Latitude & Longitude & Life history & Coastal/Inland & Location \\
\hline \multicolumn{6}{|c|}{ Mimulus guttatus (Native) } \\
\hline PED & 32.711 & -110.628 & Perennial & Inland & San Pedro River, Pinal Co., AZ \\
\hline MED & 37.829 & -120.345 & Annual & Inland & Moccasin, Tuolumne Co., CA \\
\hline REM & 38.859 & -122.410 & -- & Inland & Rumsey, Yolo Co., CA \\
\hline LMC & 38.864 & -123.084 & Annual & Inland & Yorkville, Mendocino Co., CA \\
\hline SWB & 39.036 & -123.691 & Perennial & Coastal & Sperm Whale Beach, Mendocino Co., CA \\
\hline BOG & 41.924 & -118.804 & Perennial & Inland & Bog Hot Springs, Humboldt, Co., NV \\
\hline MAR & 43.479 & -123.294 & Annual & Inland & Marshanne Landing, Douglas Co., OR \\
\hline DUN & 43.893 & -124.130 & Perennial & Coastal & Dunes, Lane Co., OR \\
\hline IM & 44.401 & -122.151 & Annual & Inland & Iron Mountain, Linn Co., OR \\
\hline $\mathrm{AHQ}$ & 44.431 & -110.813 & Perennial & Inland & Lonestar Basin Thermal Spring, Teton Co., WY \\
\hline YJS & 44.951 & -114.585 & Perennial & Inland & Yellowjacket creek, Lemhi Co., ID \\
\hline TSG & 53.419 & -131.916 & Perennial & Coastal & $\begin{array}{l}\text { Graham Island, Haida Gwaii (Queen Charlotte } \\
\text { Islands), British Columbia, Canada }\end{array}$ \\
\hline \multicolumn{6}{|c|}{ Mimulus guttatus (Introduced) } \\
\hline CRO & 50.163 & -5.293 & Perennial & -- & Crowan, Cornwall \\
\hline TRE & 50.498 & -4.465 & Perennial & -- & Tremar Coombe, Cornwall, England \\
\hline HOU & 51.097 & -1.508 & Perennial & -- & Houghton Lodge, Hampshire, England \\
\hline
\end{tabular}




\begin{tabular}{|c|c|c|c|c|c|c|}
\hline CER & & 53.006 & -3.549 & Perennial & -- & Cerrigydrudion, Denbigshire, Wales \\
\hline VIC & & 54.763 & -7.454 & Perennial & -- & Victoria Bridge, Northern Ireland \\
\hline AYR & & 55.461 & -4.625 & Perennial & -- & Ayr, Ayrshire, Scotland \\
\hline DBL & & 56.197 & -3.965 & Perennial & -- & Dunblane, Perthshire, Scotland \\
\hline том & & 57.255 & -3.368 & Perennial & -- & Tomintoul, Moray, Scotland \\
\hline PAC & & 57.355 & -3.336 & Perennial & -- & Packhorse Bridge, Speyside, Scotland \\
\hline QUA & & 60.105 & -1.227 & Perennial & -- & Quarff, Shetland Islands \\
\hline \multicolumn{7}{|c|}{ Outgroups } \\
\hline SF & M. nasutus & 45.635 & -120.914 & Annual & Inland & Sherars Falls, Wasco Co., OR \\
\hline MCN & M. cupriphilus & 37.912 & -120.724 & Annual & Inland & McNulty Mine, Calaveras, Co., CA \\
\hline CVP & M. platycalyx & 38.372 & -123.055 & Annual & Inland/Coastal & Coleman Valley Road, Sonoma Co., CA \\
\hline EBR & M. micranthus & 39.631 & -123.532 & Annual & Inland & Branscomb, Mendocino Co., CA \\
\hline DENT & M. dentilobus & NA & NA & -- & -- & NA \\
\hline
\end{tabular}




\section{FIGURES}

719 Figure 1. Location of the 22 Mimulus guttatus populations sampled in the native range in North

720 America (left-hand side panel), and in the introduced range the United Kingdom (right-hand side

721 panel). Notice the different scales in the two maps. The colour of the symbols corresponds to

722 the clades shown in the neighbour joining tree in Fig. 2.

723 Figure 2. Relationships between native (North America) and introduced (United Kingdom)

724 populations of Mimulus guttatus inferred from 1,400,000 SNPs, sampled at a density of 100,000

725 SNPs per chromosome. The neighbour joining tree was built from a matrix of pairwise genetic

726 distance ( $p$-distance) of 30 individuals of $M$. guttatus, four related taxa, and rooted with $M$.

727 dentilobus. Branches leading to introduced populations are shown in purple. The two clades

728 containing native M. guttatus in the North and South groups (see Results) are shown in blue and

729 red, respectively. All nodes at the population level have a 100/100 bootstrap support.

730 Population names as in Table 1.

731 Figure 3. Principal component analysis of twelve native (North America) and ten introduced

732 (United Kingdom) populations of Mimulus guttatus. Introduced populations cluster in the lower

733 left quadrat. Only one individual of the Iron Mountain (IM) population was included in this

734 analysis. Colours denote values at first two principal component (PC) axes. Population names as

735 in Table 1.

736 Figure 4. Evidence of hard selective sweeps within UK M. guttatus was found on 5 of the 14

737 linkage groups using SweepFinder (Nielsen et al. 2005). The figure shows selective sweeps after 
738 masking for shared sweeps between native and introduced populations (see Methods). Dashed

739 line indicates genome-wide $1 \%$ outlier cutoff based on the composite likelihood ratio (CLR)

740 statistic. Only linkage groups with sweeps exceeding $1 \%$ outlier cutoff are shown here; CLR

741 profiles for all linkage groups are shown for both native and introduced populations in the

742 supplementary materials. 


\section{SUPPLEMENTARY MATERIAL}

744 Figure S1. Distribution of genome-wide pairwise nucleotide diversity (i.e., the average number

745 of nucleotide differences per site between two sequences, $\pi$ ) in native and introduced

746 populations of the yellow monkeyflower, Mimulus guttatus. The left-hand side panel shows

747 nucleotide diversity of 10 introduced populations in the United Kingdom, and the right-hand

748 side panel shows nucleotide diversity for 10 native populations in North America (same 10 used

749 in sweep analysis). Nucleotide diversity was calculated using windows of 50,000 genotyped base

750 pairs (bp) and 1,000 bp overlapping steps.

751 Figure S2. Genome-wide pattern of pairwise nucleotide diversity $(\pi)$ in 10 introduced

752 populations of Mimulus guttatus in the United Kingdom. Each row represents one of the 14

753 major linkage groups (scaffolds). Nucleotide diversity was calculated using windows of 50,000

754 genotyped base pairs (bp) and 1,000 bp overlapping steps. The $\mathrm{x}$-axis indicates the midpoint

755 position of each window with respect to the M. guttatus $v 2.0$ reference genome

756 (www.phytozome.org).

757 Figure S3. Genome-wide of pairwise nucleotide diversity $(\pi)$ in 10 native populations of Mimulus

758 guttatus in North America (AHQ, BOG, DUN, IM, LMC, MAR, PED, SWB, TSG, YJS). Each row

759 represents one of the 14 major linkage groups (scaffolds). Nucleotide diversity was calculated

760 using windows of 50,000 genotyped base pairs (bp) and 1,000 bp overlapping steps. The $\mathrm{x}$-axis

761 indicates the midpoint position of each window with respect to the M. guttatus $v 2.0$ reference 
762 genome (www.phytozome.org).

763 Figure $S 4$. Distribution of non-synonymous $\left(\pi_{\text {non-syn }}\right)$ and synonymous $\left(\pi_{\text {syn }}\right)$ pairwise nucleotide

764 diversity in 10 introduced (left-hand side panels; United Kingdom), and in 10 native populations

765 (right-hand side panels; North America) of Mimulus guttatus.

766 Figure S5. Selective sweeps identified in introduced populations (United Kingdom) of the yellow

767 monkeyflower, Mimulus guttatus, across the 14 major linkage groups (scaffolds) in this species.

768 The composite likelihood ratio (CLR) measures departures in the site frequency spectrum from

769 background levels observed within linkage groups, and provide evidence of selective sweeps

770 (Nielsen et al. 2005). Black dots indicate CLR scores above the $1 \%$ outlier cutoff, after masking

771 (omitting) regions with significant CLR scores in North American samples. The x-axis indicates

772 the position in base pairs with respect to the $M$. guttatus $v 2.0$ reference genome

773 (www.phytozome.org). For full details of the analysis see Methods section.

774 Figure S6. Evidence for reduced pairwise nucleotide diversity $\left(\pi\right.$ and $\pi_{\text {syn }}$ ) in genes located

775 within (sweep) vs. outside selective sweeps (no sweep) of introduced populations of Mimulus

776 guttatus in the United Kingdom. The left-hand side panel shows pairwise nucleotide diversity

777 across all sites within a gene $(\pi)$, and the left-hand side panel shows pairwise nucleotide

778 diversity in synonymous sites only $\left(\pi_{\text {syn }}\right)$. For the left panel, nucleotide diversity was calculated

779 using windows of 50,000 genotyped base pairs (bp) and 1,000 bp overlapping steps.

780 Synonymous site nucleotide diversity was calculated for all genes within swept region. Boxplots

781 show the median (horizontal line), $1^{\text {st }}$ and $3^{\text {rd }}$ quartiles (top and bottom of the box), and the 1.5 
782 interquartile range (whiskers).

783 Figure S7. Genome-wide distribution of genotyped base pairs per individual across ten

784 individuals from ten introduced populations of Mimulus guttatus in the United Kingdom (UK).

785 The chart shows, for instance, that nine out of ten individuals were successfully genotyped at

786 more than 18 million base pairs.

787 Figure S8. Principal component analysis (PCA) of 30 individuals of Mimulus guttatus from both

788 native and introduced ranges, including multiple individuals of the Iron Mountain (IM)

789 population. This PCA was based on 10,000 SNPs per linkage group for a total of 140,000 SNPs

790 across the genome. Introduced populations fall in the bottom left quadrat. Population codes are

791 defined in Table 1.

792 Table S1. Annotated list of 299 genes located within the selective sweeps identified in

793 introduced populations of the yellow monkeyflower, Mimulus guttatus, in the United Kingdom.

794 The location of each gene (start and end), and of the selective sweep that contains it, is given in

795 base pairs (bp) with respect to the M. guttatus v. 2.0 reference genome (www.phytozome.org).

796 Table S2. Annotated list of a subset of 28 genes within the selective sweeps described in Table

797 S1 that display reduced synonymous diversity $\left(\pi_{\text {syn }}<0.01\right)$.

798 Supplementary File: Bioinformatics. Commands used for sequence analysis, quality control, and 799 genotyping. 

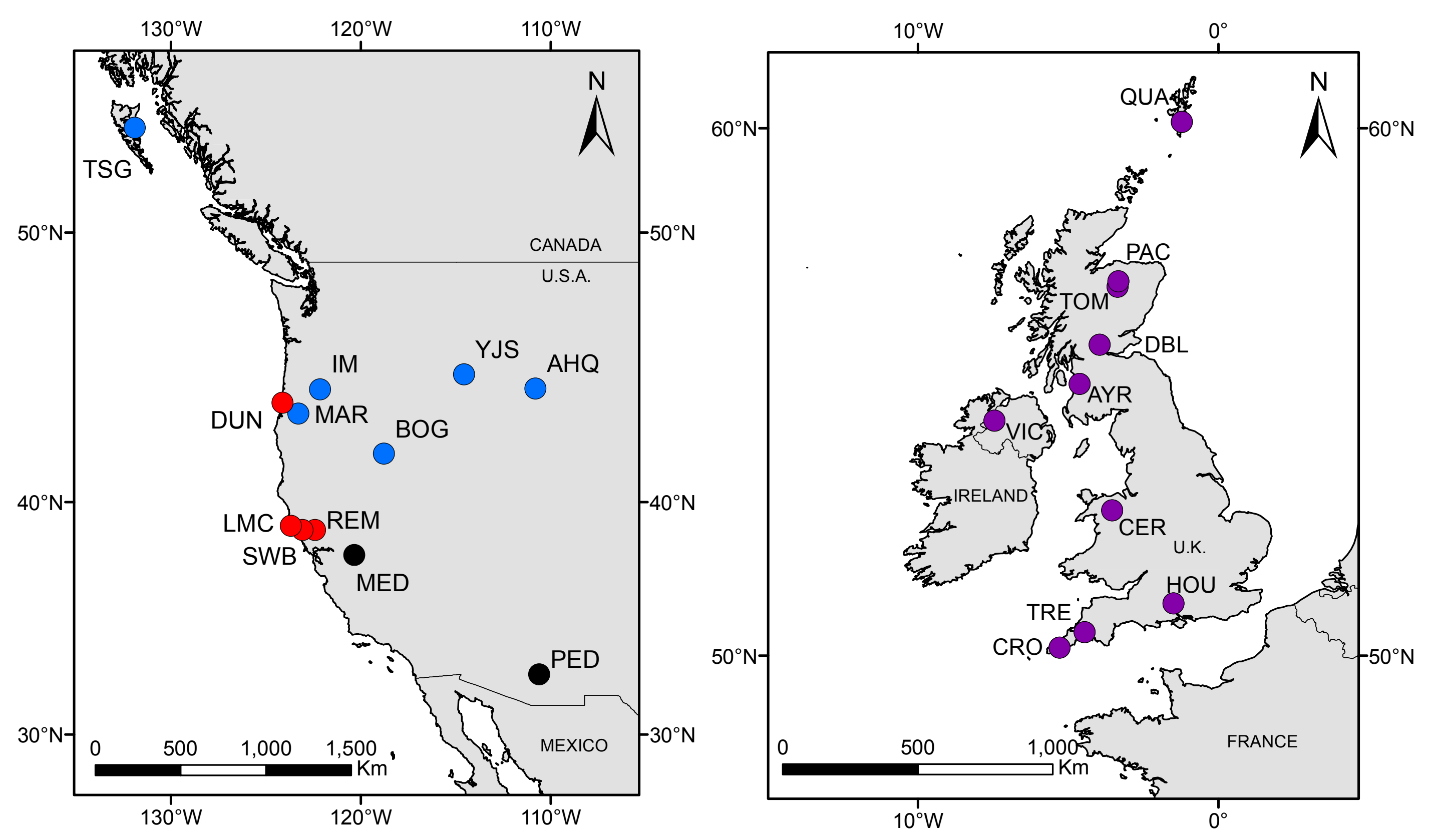


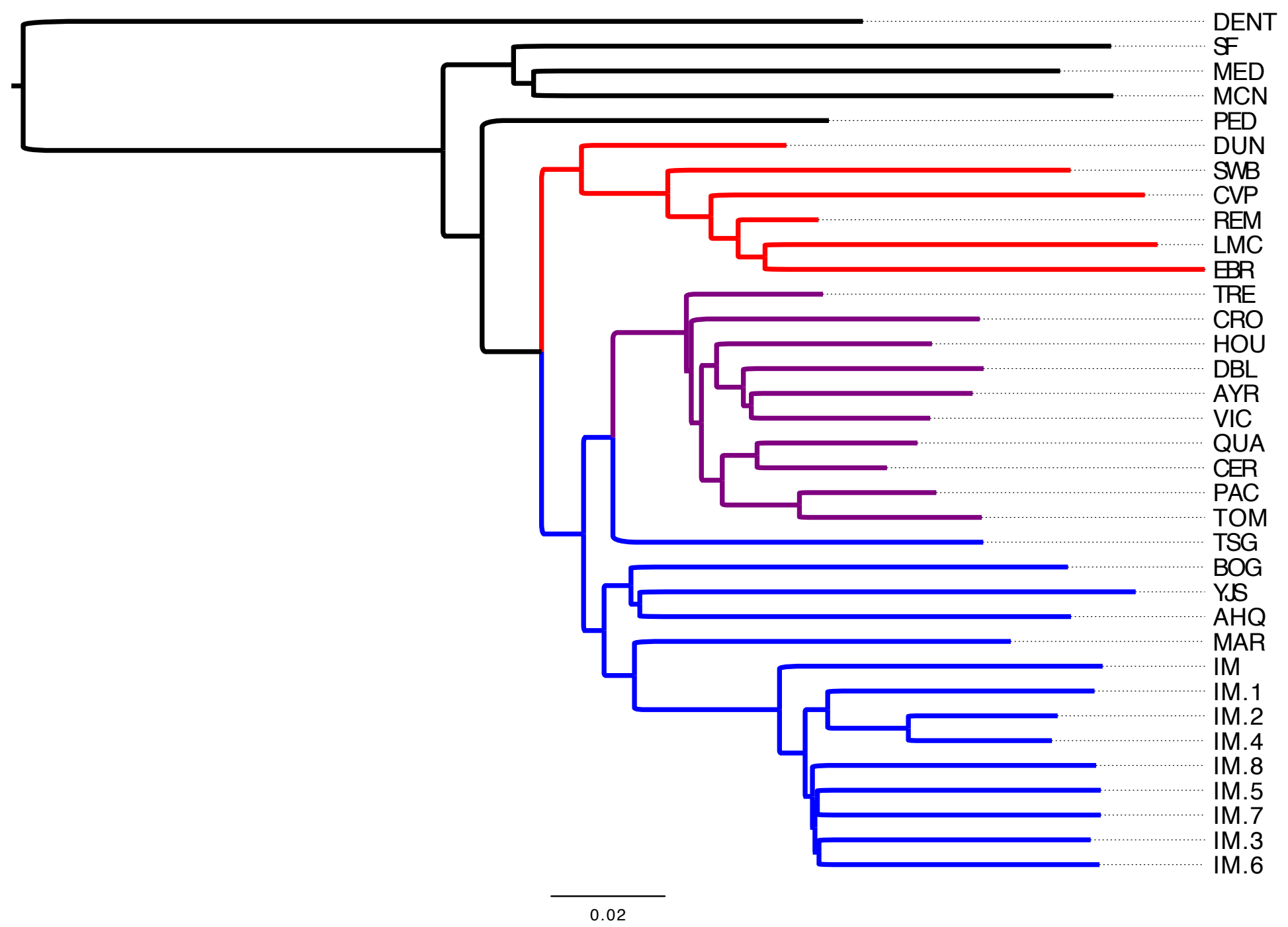




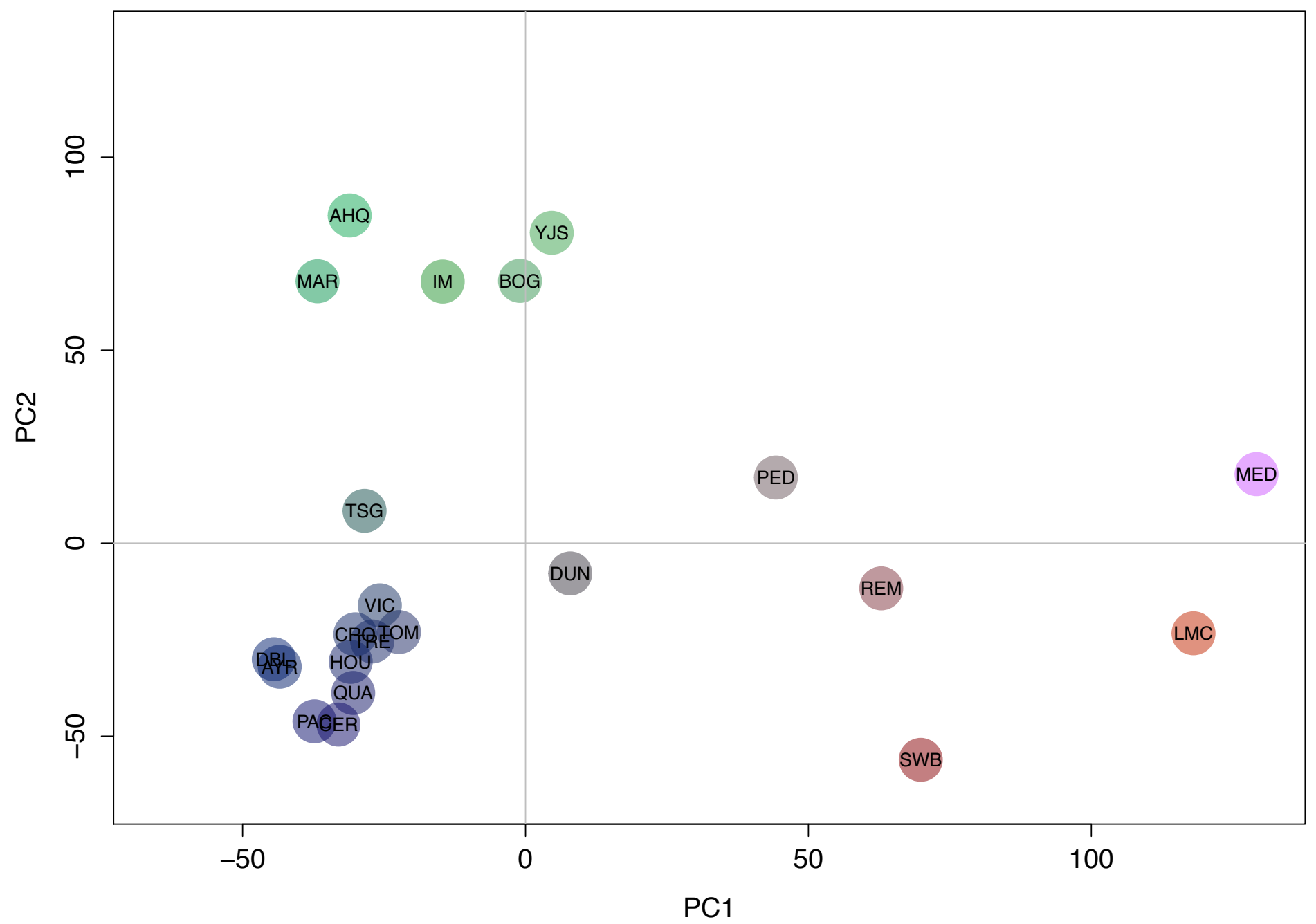




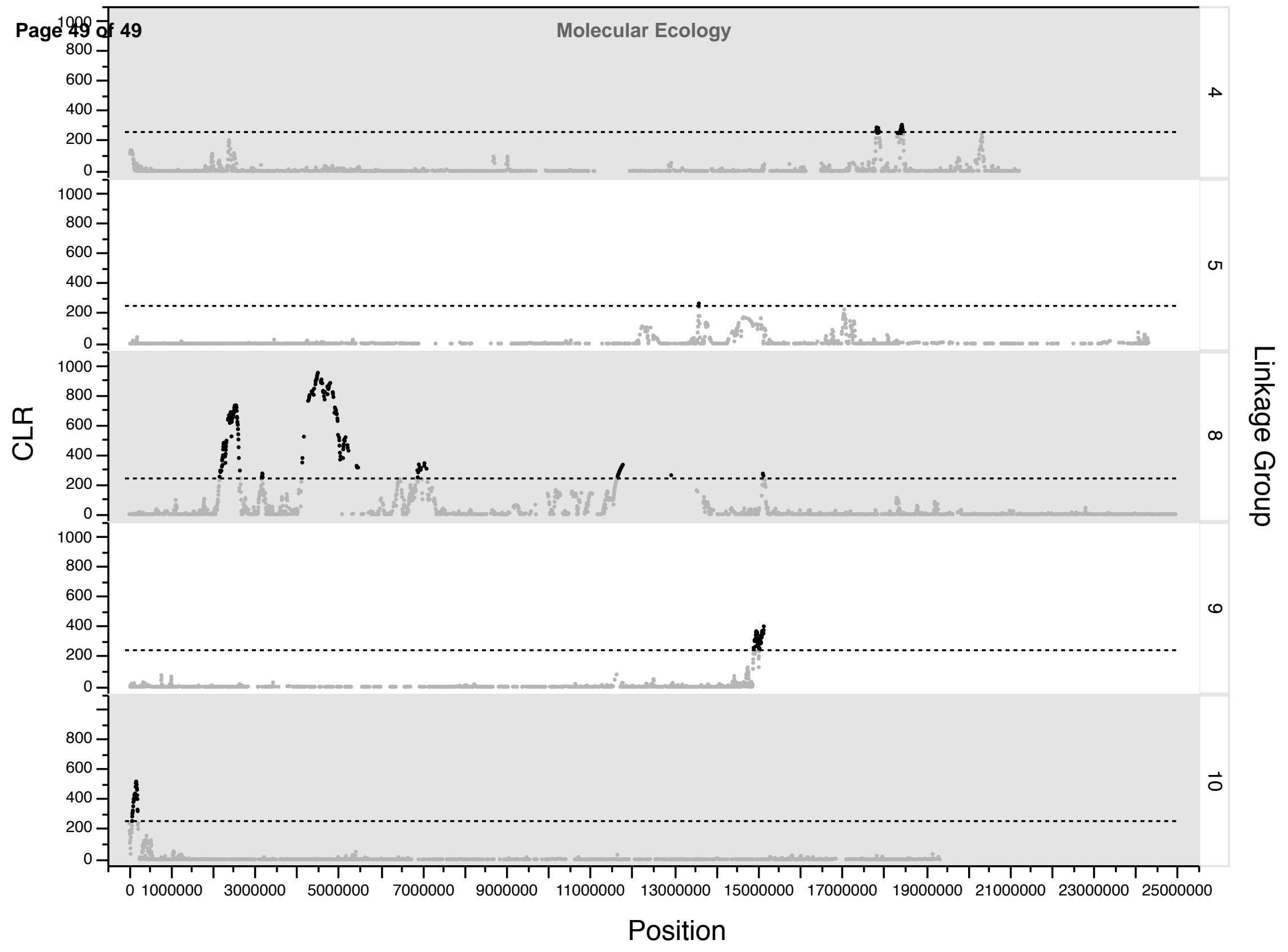

